\title{
The Effect of Polyethylene Glycol (PEG) on the Performance of Natural Zeolite-PVA Hybrid Ceramic Membrane for Desalination
}

\author{
Anwar Ma'ruf 1, *, Moechammad Agus Salim Al Fathoni², Agus Mulyadi Purnawanto ${ }^{3}$, \\ Linatul Chulqi ${ }^{1}$ \\ ${ }^{1}$ Chemical Engineering Department, Faculty of Engineering and Science, Universitas Muhammadiyah Purwokerto, Purwokerto, Indonesia \\ ${ }^{2}$ Civil Engineering Department, Faculty of Engineering and Science, Universitas Muhammadiyah Purwokerto, Purwokerto, Indonesia \\ ${ }^{3}$ Agrotechnology Department, Faculty of Agriculture, Universitas Muhammadiyah Purwokerto, Purwokerto, Indonesia
}

Email address:

anwarump@yahoo.com (A. Ma’ruf), agus@gtsshop.com (M. A. S. Al Fathoni), agoesmp@gmail.com (A. M. Purnawanto), clinatul@yahoo.com (L. Chulqi)

${ }^{*}$ Corresponding author

\section{To cite this article:}

Anwar Ma'ruf, Moechammad Agus Salim Al Fathoni, Agus Mulyadi Purnawanto, Linatul Chulqi. The Effect of Polyethylene Glycol (PEG) on the Performance of Natural Zeolite-PVA Hybrid Ceramic Membrane for Desalination. American Journal of Chemical Engineering. Vol. 8, No. 1, 2020, pp. 1-4. doi: 10.11648/j.ajche.20200801.11

Received: January 30, 2020; Accepted: February 17, 2020; Published: February 25, 2020

\begin{abstract}
The seawater desalination process currently uses membrane technology because of relatively lower investment and energy requirements. The process of seawater desalination using membrane process technology can be done in 3 methods, namely reverse osmosis (RO), distillation membrane (membrane distillation / MD) and pervaporation process (PV). This study will examine the performance of a hybrid membrane developed from natural zeolite- $\mathrm{TiO}_{2}$ with polyvinyl alcohol (PVA) in addition to polyethylene glycol (PEG) for desalination of seawater. The addition of PEG to the PVA polymer solution (dope) will increase the membrane resistance $\left(R_{m}\right)$ and seawater rejection. The higher rejection is achieved of $93.77 \%$ at the addition of $6 \%$ PEG. Fouling resistance $\left(\mathrm{R}_{\mathrm{f}}\right)$ isn't affected by PEG concentration. The fouling resistance has good linearity and stability at the addition of $6 \%$ PEG.
\end{abstract}

Keywords: Hybride Membrane, Desalination, Natural Zeolite

\section{Introduction}

The process of seawater distillation for industry usually uses multistage flash evaporators (MSF) or multi-effect distillation (MED). This method is not suitable for small industries or for household-scale because it requires large investment and energy. The seawater desalination process currently uses membrane technology because of relatively lower investment and energy requirements. The process of seawater desalination using membrane process technology can be done in 3 methods, namely reverse osmosis (RO), membrane distillation (MD) and pervaporation process (PV) [1].

Membranes used in the desalination process generally use the polymer membranes. However, this membrane has disadvantages such as low flux, low thermal and chemical stability. To improve polymer membranes, the hybrid membranes can be used, namely a mixture of polymer and non-polymer. One of the non-polymer membranes is a ceramic membrane. The ceramic membranes are porous, because of that, for the desalination process, the ceramics only as of the support membranes. The hybrid membrane can be achieved by the dip-coating process of the ceramics support membrane by using a polymer solution. The use of this composite membrane aims to increase membrane flux, thermal stability, and chemical stability.

There were several researchers that use or produce hybrid membranes or ceramic composite membranes for any purpose. Gongping et al.[2] produced a hybrid membrane from ceramic support with several polymers such as hydrophobic polydimethylsiloxane (PDMS) and hydrophilic poly (vinyl alcohol) (PVA), chitosan (CS) and 
polyelectrolytes for pervaporation process. Biron et al. [3] produced a hybrid membrane from polyamide 66 (PA66) deposited by dip coating on the inner surface of $\alpha$-aluminabased $\left(\mathrm{Al}_{2} \mathrm{O}_{3}\right)$ micro-porous tube for ultrafiltration of protein. Jeong et al. [4, 5] produce pyrophyllite-alumina composite ceramic membranes for treating of municipal wastewater.

The hybrid ceramic membranes or ceramic composite membranes can be used for desalination process [6 - 9]. The main problems in the membrane separation process are productivity and purity. The productivity of membrane process will decrease due to fouling of the membrane [10, 11]. This study will examine the performance of a hybrid membrane developed from natural zeolite- $\mathrm{TiO}_{2}$ with polyvinyl alcohol (PVA) in addition to polyethylene glycol (PEG) for desalination of seawater.

\section{Materials and Methods}

\subsection{Materials}

Natural zeolite and starch were purchased from the local market at Purwokerto, Indonesia. Polyvinyl alcohol (PVA) and citric acid were obtained from Merck. PEG 400 was obtained from Bratachem, Indonesia.

\subsection{Ceramic Membrane Development}

The development of ceramic membrane support was conducted by the methods as previous work [12].

\subsection{Hybrid Membrane Development}

The composite membrane was developed by the dipcoating process. PVA polymer and citric acid (crosslinker) were dissolved in the water and then homogenized and heated by an ultrasound bath at $60^{\circ} \mathrm{C}$ for 30 minutes. The PEG was added to the dope solution at various concentrations $(0,2 \%, 4 \%, 6 \%)$. Ceramic membrane support was dip-coated at the polymer solution for 24 hours. The hybrid ceramic membrane was drying at $60^{\circ} \mathrm{C}$ for 6 hours and then at $120^{\circ} \mathrm{C}$ for 2 hours [13].

\subsection{Desalination Set up}

The desalination process was done by cross-flow proses (Figure 1). Seawater was filled in the feed tank. Then pumped to the flat sheet of hybrid ceramic membrane at the constant pressure. The permeate was collected and weighed periodically. The retentate was recycled to the feed tank.

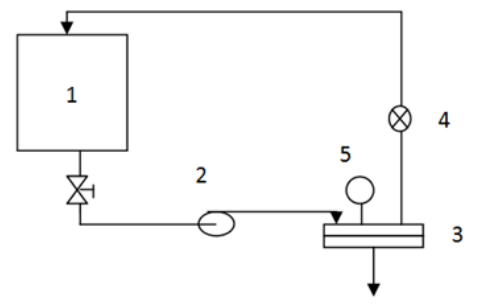

1. Feed tank

2. Pump

3. Membrane module

4. Valve

5. Pressure gauge

\section{Results and Discussion}

\subsection{Effect of PEG Concentration on Membrane Resistance (Rm)}

Membrane resistance is defined as the function flux of clean water during filtration. The permeate flux through a membrane is often described as the applied transmembrane pressure driving force, TMP, divided by the resistance to mass transfer, R, and the permeate viscosity. For pure water filtration, $\mathrm{R}$ will represent the resistance to mass transfer associated with the clean membrane [14]. Mathematically can be written as:

$$
J_{o}=\frac{T M P}{\mu \cdot R_{m}}
$$

Where Jo is the flux of clean water $\left(\mathrm{m}^{3} / \mathrm{m}^{2} . \mathrm{s}\right)$, TMP is transmembrane pressure $(\mathrm{Pa}), \mu$ is the viscosity of clean water $(\mathrm{Pa} . \mathrm{s})$ and $\mathrm{Rm}$ is membrane resistance $\left(\mathrm{m}^{-1}\right)$.

Figure 2 shows the effect of the PEG concentration on the membrane resistances. The value of hybrid membrane natural zeolite - PVA is $5.20 \times 1012 \mathrm{~m}^{-1}$. Biron at al. [3] reported the ceramic support developed from $\alpha$-alumina showed the membrane resistance of $0.83 \times 1013 \mathrm{~m}^{-1}$. The addition of PEG on the polymer concentration will increase the value of membrane resistance. The value of hybrid membrane are $1.42 \times 1013 \mathrm{~m}^{-1}, 1.56 \times 1013 \mathrm{~m}^{-1}$, and $1.95 \times 1013 \mathrm{~m}^{-1}$ in addition of 2, 4, 6\% PEG respectively. Biron et al. [3] also reported that the hybrid membrane of $\alpha$-alumna - PA 66 had the value of membrane resistance of $2.85 \times 1013 \mathrm{~m}^{-1}$.

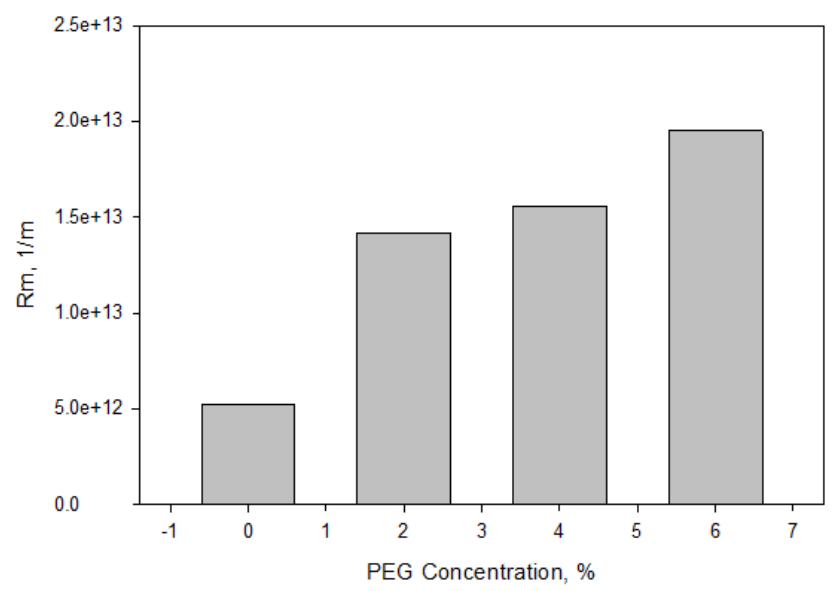

Figure 2. The value of membrane resistance at the various PEG concentrations.

\subsection{Effect of PEG Concentration on Membrane Flux and Rejection}

Figure 3 shows the flux of seawater during the reverse osmosis process. The flux of seawater is decreasing with the increase of PEG concentration. Figure 4 shows the rejection of seawater during the reverse osmosis process. The higher PEG concentration results in a higher rejection. Without the addition of PEG, the rejection of the natural zeolite-PVA hybrid ceramic membrane is only $63.16 \%$. The maximum 
rejection is achieved of $93.77 \%$ at the PEG concentration of $6 \%$. Kujawa et al. [9] reported that rejection of seawater achieved $98 \%$ by using $\mathrm{TiO}_{2}$ and $\mathrm{Al}_{2} \mathrm{O}_{3}$ membrane modification with alkylsilanes. Xie et al. [7] reported that at the utilization of a hybrid membrane from polyvinyl alcohol/maleic acid/tetraethyl orthosilicate (PVA/MA/TEOS) for pervaporation process of seawater, the salt $(\mathrm{NaCl})$ rejection of the membrane achieved $99 \%$. This was mainly due to the non-volatile nature of the $\mathrm{NaCl}$ compound and hydrophilic nature of the hybrid PVA/MA/TEOS membrane. In PV separation of aqueous salt solution, water molecules preferentially diffuse and permeate into the membrane. $\mathrm{Al}$ Mayyahi and Deng [15] reported that the rejection of $\mathrm{NaCl}$ achieved $98 \%$ at the desalination process using photoresponsive $\mathrm{ZnO}$ polyamide thin film nanocomposite membrane.

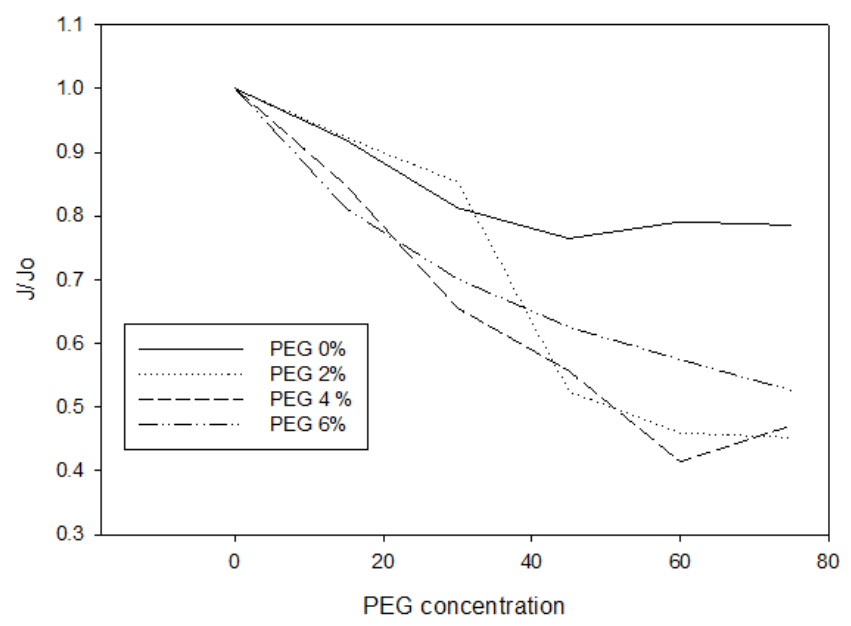

Figure 3. The flux of desalination of seawater at the various PEG concentrations.

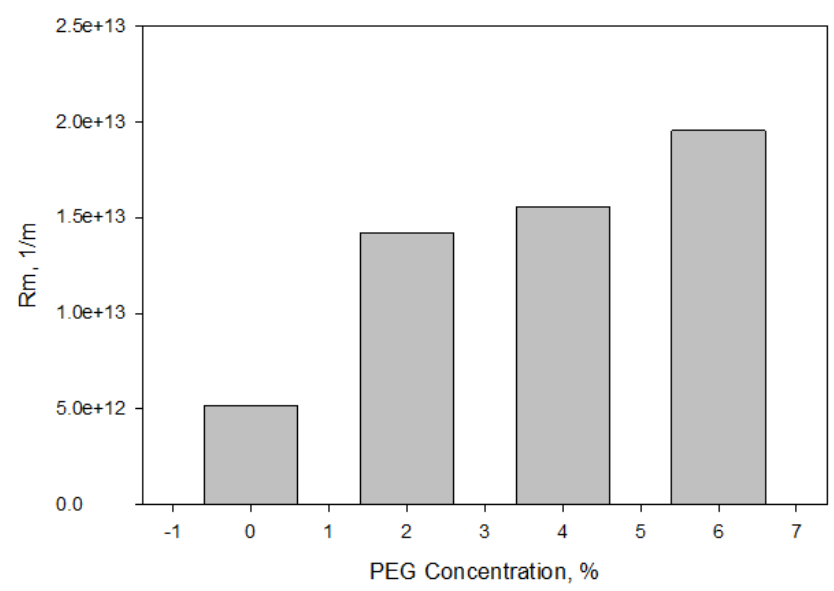

Figure 4. Rejection of seawater at the various PEG concentrations.

\subsection{Effect of PEG Concentration on Fouling Resistance $\left(\boldsymbol{R}_{f}\right)$}

The permeate flux through a membrane during the filtration process is described as the applied transmembrane pressure driving force, TMP, divided by the total resistance to mass transfer, Rt, and the permeate viscosity. Mathematically can be written as:

$$
J=\frac{T M P}{\mu \cdot R_{t}}
$$

Where $R_{t}$ is the sum of $R_{m}+R_{f}$. $R_{f}$ can be determined by the equation:

$$
\mathrm{R}_{\mathrm{f}}=\mathrm{R}_{\mathrm{t}}-\mathrm{R}_{\mathrm{m}}
$$

Figure 5 shows the fouling resistance $\left(\mathrm{R}_{\mathrm{f}}\right)$ during the desalination of seawater at the various PEG concentrations. The figure shows that the fouling resistance of the membrane with $6 \%$ PEG has good linearity and stability. While the fouling resistance of the membrane with $2 \%$ and $4 \%$ PEG are poor of linearity and stability. The fouling resistance increases significantly after 30 minutes. The linearity of membranes is shown in Table 1. The figure shows that at the time of 75 minutes, the fouling resistance at various PEG concentrations achieved the same value of $1.7 \times 1013 \mathrm{~m}^{-1}$.

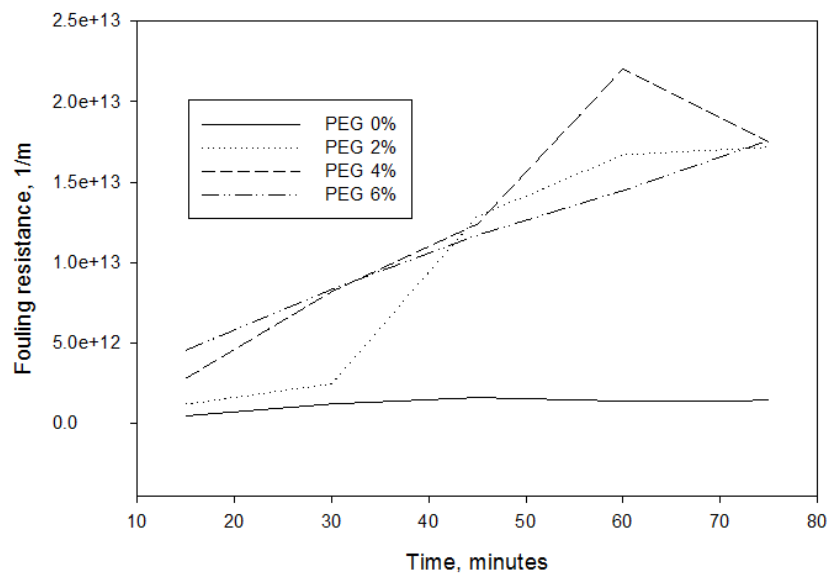

Figure 5. The fouling resistance during desalination at the various PEG concentrations.

Table 1. Linearity equation of fouling resistance.

\begin{tabular}{lll}
\hline PEG Concentration & Equation & $\mathbf{R}^{2}$ \\
\hline 0 & $\mathrm{y}=1.10^{10} \mathrm{x}+6.10^{11}$ & 0.5575 \\
2 & $\mathrm{y}=3.10^{11} \mathrm{x}-4.10^{12}$ & 0.8933 \\
4 & $\mathrm{y}=3.10^{11} \mathrm{x}-4.10^{11}$ & 0.8174 \\
6 & $\mathrm{y}=2.10^{11} \mathrm{x}+2.10^{12}$ & 0.9967 \\
\hline
\end{tabular}

\section{Conclusion}

The addition of PEG to the PVA polymer solution (dope) will increase the membrane resistance $(\mathrm{Rm})$ and seawater rejection. The higher rejection is achieved of $93.77 \%$ at the addition of $6 \%$ PEG. Fouling resistance (Rf) isn't affected by PEG concentration. The fouling resistance has good linearity and stability at the addition of $6 \%$ PEG. The characteristics of hybrid ceramic membrane form natural zeolite PVA/PEG must be modified to increase the flux and rejection coeffiecient.

\section{Acknowledgements}

The authors acknowledge to Ministry of Research 
Technology and Higher Education of Indonesia for funding this research.

\section{References}

[1] M. Elma, C. Yacou, D. K. Wang, S. Smart, and J. C. Diniz, "Microporous Silica Based Membranes for Desalination," Water, vol. 4, pp. 629-649, 2012.

[2] G. Liu, W. Wei, W. Jin, and N. Xu, "Polymer/ceramic composite membranes and their application in pervaporation process," Chinese J. Chem. Eng., vol. 20, no. 1, pp. 62-70, 2012.

[3] D. da S. Biron, P. Poletto, J. Duarte, M. Zeni, C. Perez, and V. dos Santos, "Preparation and Characterization of PA66/Alumina Composite Membrane Dionisio," Mater. Res., vol. 18, no. 4, pp. 748-755, 2015.

[4] Y. Jeong, S. Lee, S. Hong, and C. Park, "Preparation, characterization and application of low-cost pyrophyllitealumina composite ceramic membranes for treating lowstrength domestic wastewater," J. Memb. Sci., vol. 536, pp. 108-115, 2017.

[5] Y. Jeong, Y. Kim, Y. Jin, S. Hong, and C. Park, "Comparison of filtration and treatment performance between polymeric and ceramic membranes in anaerobic membrane bioreactor treatment of domestic wastewater," Sep. Purif. Technol., vol. 199, pp. 182-188, 2018.

[6] P. S. Goh and A. F. Ismail, "A review on inorganic membranes for desalination and wastewater treatment," Desalination, vol. 434, pp. $130-155,2018$.

[7] Z. Xie, D. Ng, M. Hoang, and J. Zhang, "Study of Hybrid PVA / MA / TEOS Pervaporation Membrane and Evaluation of Energy Requirement for Desalination by Pervaporation," Environ. Res. Public Heal., vol. 15, no. 1913, pp. 1-18, 2018.

[8] S. Tao, Y. Xu, J. Gu, H. Abadikhah, J. Wang, and X. Xu, "Preparation of high-efficiency ceramic planar membrane and its application for water desalination," J. Adv. Ceram., vol. 7, no. 2, pp. 117-123, 2018.

[9] J. Kujawa, S. Cerneaux, W. Kujawski, and K. Knozowska, "Hydrophobic Ceramic Membranes for Water Desalination," Appl. Sci., 7, pp. 1-11, 2017.

[10] A. Ruiz-Garcia, N. Melian-Mantel, and I. Nuez, "Short Review on Predicting Fouling in RO Desalination," Membranes (Basel)., vol. 7, no. 62, pp. 1-17, 2017.

[11] P. S. Goh, W. J. Lau, M. H. D. Othman, and A. F. Ismail, "Membrane fouling in desalination and its mitigation strategies," Desalination, vol. 425, no. October, pp. 130-155, 2018.

[12] A. Ma'Ruf and M. A. S. Al Fathoni, "Development of porous ceramic membrane from natural zeolite - Clay for microfiltration," IOP Conf. Ser. Mater. Sci. Eng., vol. 403, no. 1, pp. 0-5, 2018.

[13] A. Ma'ruf, A. S. Al Fathoni, A. M. Purnawanto, and R. A. Kusumajati, "Development of Hybrid Membrane from Clay / TiO 2 -PVA for Batik Wastewater Treatment," Nat. Environ. Pollut. Technol., vol. 18, no. 4, pp. 1249-1255, 2019.

[14] D. J. Miller, S. Kasemset, D. R. Paul, and B. D. Freeman, "Comparison of membrane fouling at constant flux and constant transmembrane pressure conditions," J. Memb. Sci., vol. 454, pp. 505-515, 2014.

[15] A. Al Mayyahi and B. Deng, "Efficient water desalination using photo-responsive $\mathrm{ZnO}$ polyamide thin film nanocomposite membrane," Env. Chem. Let., vol. 16, no. 4., pp. 1469-1475, 2018. 